\title{
MAF and fluorescence play their part
}

\author{
David J S Birch ${ }^{1}$, Marcia Levitus ${ }^{2}$ and Yves Mély ${ }^{3}$ \\ ${ }^{1}$ The Photophysics Research Group, University of Strathclyde, Department of Physics, SUPA, John \\ Anderson Building, 107 Rottenrow, Glasgow, G4 ONG, United Kingdom
}
${ }^{2}$ School of Molecular Sciences and The Biodesign Institute, Arizona State University, PO Box 875601 , Tempe AZ, 85287-5601, USA.
${ }^{3}$ Laboratoire de Bioimagerie et Pathologies, UMR7021 CNRS, Faculté de Pharmacie, Université de Strasbourg, Cedex, 67401 Illkirch, France

E-mail: djs.birch@strath.ac.uk

Dear Readers

In last year's Editorial [1] we highlighted the increase in the2019 Impact Factor of Methods and Applications in Fluorescence (MAF) and this year we are pleased to report the journal continues to maintain its lead in the field by a substantial margin with an impact Factor of 2.8.

The past year has again seen strong evidence of the high quality of work in fluorescence throughout the journal's Special Issues, Topical Reviews, Tutorials, Perspectives and regular articles.

As we looked forward in last year's editorial we flagged up the forthcoming Special Issue on fluorescence lifetime imaging microscopy (FLIM) edited by Simon Ameer-Beg, Klaus Suhling and Marina Kuimova [2]. This exciting issue certainly lived up to its promise with 21 articles spanning the methods, photophysics and applications of FLIM. These included emerging FLIM techniques such as video rate imaging using single-photon avalanche diode arrays [3] as well as applications based on some of the cornerstones of fluorescence such as Forster resonance energy transfer (FRET) [4-6].

In 2018 we launched a Tutorial section for MAF and in 2020 this important didactical approach to fluorescence led to three Tutorials [6-8], so please keep authorship of these in mind as they are a big help to newcomers to fluorescence.

The journal was also well-served with five Topical Reviews throughout 2020. These included one by Alexander Demchenko on the all too often neglected competitor of fluorescence, namely photobleaching of organic fluorophores [9]. Already this review is making its mark with 6 citations in 2020 and other articles are already at the same count. The whole area of photostability has seen a renaissance in recent years because of its relevance to single molecule detection and worthy of special mention in this area is the article on DNA origami nanoantennas by Lennart Grabenhorst, Kateryna Trofymchuk, Florian Steiner, Viktorija Glembockyte and Philip Tinnefeld [10], which received a massive 570 downloads within the first 30 days of publication.

As we all hope that 2021 will be the year of emergence from COVID-19, MAF like the rest of us continues to plan for the days ahead. With this in mind do keep a watchful eye out for the new MAF 
webinars in 2020. Likely topics include super-resolution microscopy, FLIM, fluorescent probes and nanoparticles.

We also hope the postponed MAF conference series in Gothenburg can go ahead in September 2021 so once again we can together share our knowledge of fluorescence in the best possible way.

As one of the most informative research techniques on biomolecular systems fluorescence is undoubtedly playing its part in understanding and mastering COVID-19 with fluorescence-based research and tests for SARS-CoV-2 already emerging. Given MAF's leadership in the field we look forward to receiving fluorescence papers of relevance to the pandemic.

Finally on behalf of the Editorial Board and Institute of Physics Publishing we thank all the MAF authors and reviewers for their hard work in supporting the family of fluorescence through the journal and wish you all a happy and ever-improving year ahead.

1. MAF leads fluorescence into the new decade David J S Birch, Marcia Levitus and Yves Mély. 2019 Methods Appl. Fluoresc. 8010401

2. Special issue on fluorescence lifetime imaging (FLIM): from fundamentals to applications Simon Ameer-Beg, Klaus Suhling and Marina Kuimova. 2020 Methods Appl. Fluoresc. 8040401

3. Wide-field time-gated SPAD imager for phasor-based FLIM application. Arin Ulku, Andrei Ardelean, Michel Antolovic, Shimon Weiss, Edoardo Charbon, Claudio Bruschini and Xavier Michalet. 2020 Methods Appl. Fluoresc. 8024002.

4. Exploring protein-protein interactions with large differences in protein expression levels using FLIMFRET Julien Godet and Yves Mély. 2020 Methods Appl. Fluoresc. 8014007

5. Automated screening of AURKA activity based on a genetically encoded FRET biosensor using fluorescence lifetime imaging microscopy.

Florian Sizaire, Gilles Le Marchand, Jacques Pécréaux, Otmane Bouchareb and Marc Tramier. 2020 Methods Appl. Fluoresc. 8024006

6. Förster resonance energy transfer-what can we learn and how can we use it? Herbert Schneckenburger. 2020 Methods Appl. Fluoresc. 8013001

7. Tutorial: measurement of fluorescence spectra and determination of relative fluorescence quantum yields of transparent samples Marcia Levitus. 2020 Methods Appl. Fluoresc. 8033001

8. On the origin and correction for inner filter effects in fluorescence Part l: primary inner filter effect-the proper approach for sample absorbance correction Joseph Kimball, Jose Chavez, Luca Ceresa, Emma Kitchner, Zhangatay Nurekeyev, Hung Doan, Mariusz Szabelski, Julian Borejdo, Ignacy Gryczynski and Zygmunt Gryczynski. 2020 Methods Appl. Fluoresc. 8 033002

9. Photobleaching of organic fluorophores: quantitative characterization, mechanisms, protection Alexander P Demchenko. 2020 Methods Appl. Fluoresc. 8022001

10. Fluorophore photostability and saturation in the hotspot of DNA origami nanoantennas Lennart Grabenhorst, Kateryna Trofymchuk, Florian Steiner, Viktorija Glembockyte and Philip Tinnefeld. 2020 Methods Appl. Fluoresc. 8024003 